\title{
Librarians Do It Differently: Comparative Usability Testing with Students and Library Staff
}

\author{
Nancy B. Turner \\ Syracuse University, USA
}

\begin{abstract}
Our experience as librarians suggests that library staff search and locate library resources differently than college students. We bring to our work knowledge about library collections and search tool functionality that may inform our strategies for finding library resources. Through our training and experience, we have developed more accurate mental models for the information universe for which our library website is a portal. The purpose of this research is to explore that hypothesis and if it has merit, to articulate those differences in information seeking behaviors, particularly search strategy and tool use. As those patterns of difference are identified, the findings may be used to improve the usability of the website for students as well as illuminate real student behaviors for library staff.
\end{abstract}

In general, library staff used different strategies, selected different tools and used facets and search limits in ways that were different than students carrying out the same tasks. Their "preknowledge" about library collections and differences in how search tools function informed their search strategies. Students were more interested in efficiency and assumed a "Googlelike" search functionality when presented with a search box.

\section{Introduction}

Our experience as librarians suggests that library staff search and locate library resources differently than college students. We bring to our work knowledge about library collections and search tool functionality that may inform our strategies for finding library resources. Through our training and experience, we have developed more accurate mental models for the information universe for which our library website is a portal. The purpose of this research is to explore that hypothesis and if it has merit, to articulate those differences in information seeking behaviors, particularly search strategy and tool use. As those patterns of difference are identified, the findings may be used to improve the usability of the website for students as well as illuminate real student behaviors for library staff.

\section{Related Literature}

The current exploration relates to several bodies of literature, including research on the information seeking of college students and how it develops through increased exposure to academic library resources and information literacy. Recent study of mental models in information seeking is also of interest, as mental models impact how students and library staff approach the use of search tools on the library website. The research methodology draws upon the usability testing literature, particularly as it relates to academic websites and how they compare with tools with which students are most familiar.

Lippincott ${ }^{1}$ writes that NetGen students perceive the Web as their information "universe." This perception differs from that of librarians who think of the library as the starting place for research. In their review of library subject guide use, Reeb and Gibbons ${ }^{2}$ also reference a disconnect of mental models that students and librarians have as to how information is organized. Students' expectations of information systems are influenced by their experience with robust retrieval tools that fit their personal needs. Subject guides need to be contextual for students as they fulfill their course assignments.

Researchers at $\mathrm{MIT}^{3}$ looked at all types of information seeking behavior for graduate and undergraduate students, using interviews and photo diaries. Their research demonstrates some differences between the two populations, where 
graduate students demonstrate more complex, deeper information seeking skills. Although graduate students proved somewhat more successful with known items, undergraduates are more efficient in topical searching. This dichotomy between efficiency and accuracy is relevant our research, as similar differences emerged between students and library staff.

Yan Zhang 4 explored undergraduate college students' mental models of the Internet for information seeking. He used several methods, including interviews and the elicitation of drawings. Successful use of an information retrieval system requires understanding four components: information source, information organization schema, search mechanism, and interface. Students form their mental models of search engines based on system cues and feedback. Zhang reports that "several students regarded that there were people sitting behind 'a curtain,' searching everything, and getting back results to them." 5 The literature indicates that students may come to the website with naïve ideas about how the search tools work and what to expect of results.

Usability expert Jakob Nielsen's ${ }^{6}$ research demonstrates that users have developed a firm mental model of how a search tool is supposed to work. Most of our students bring those expectations to their work with the library-offered search and discovery tools. Mental models are developed through experience, and improvement of the mental model depends on system cues delivered with search results.

More specific to students' use of library catalogs is Dimitroff' $\mathrm{s}^{7}$ research on mental models and bibliographic retrieval systems. Her results demonstrated that there is a strong relationship between the completeness of a mental model and the success of a search, with implications for both system design and instruction. Experience will have an influence on the development of one's mental model as well as instruction or education. To support the development of more accurate mental models, systems must provide users with a robust search engine as well as feedback mechanisms that enhance their learning.

\section{Research Context}

In the summer of 2009 Syracuse University Library launched a freshly-designed website with new search and discovery tools and a re-designed search box.

\section{Figure 1 - Library Home Page}

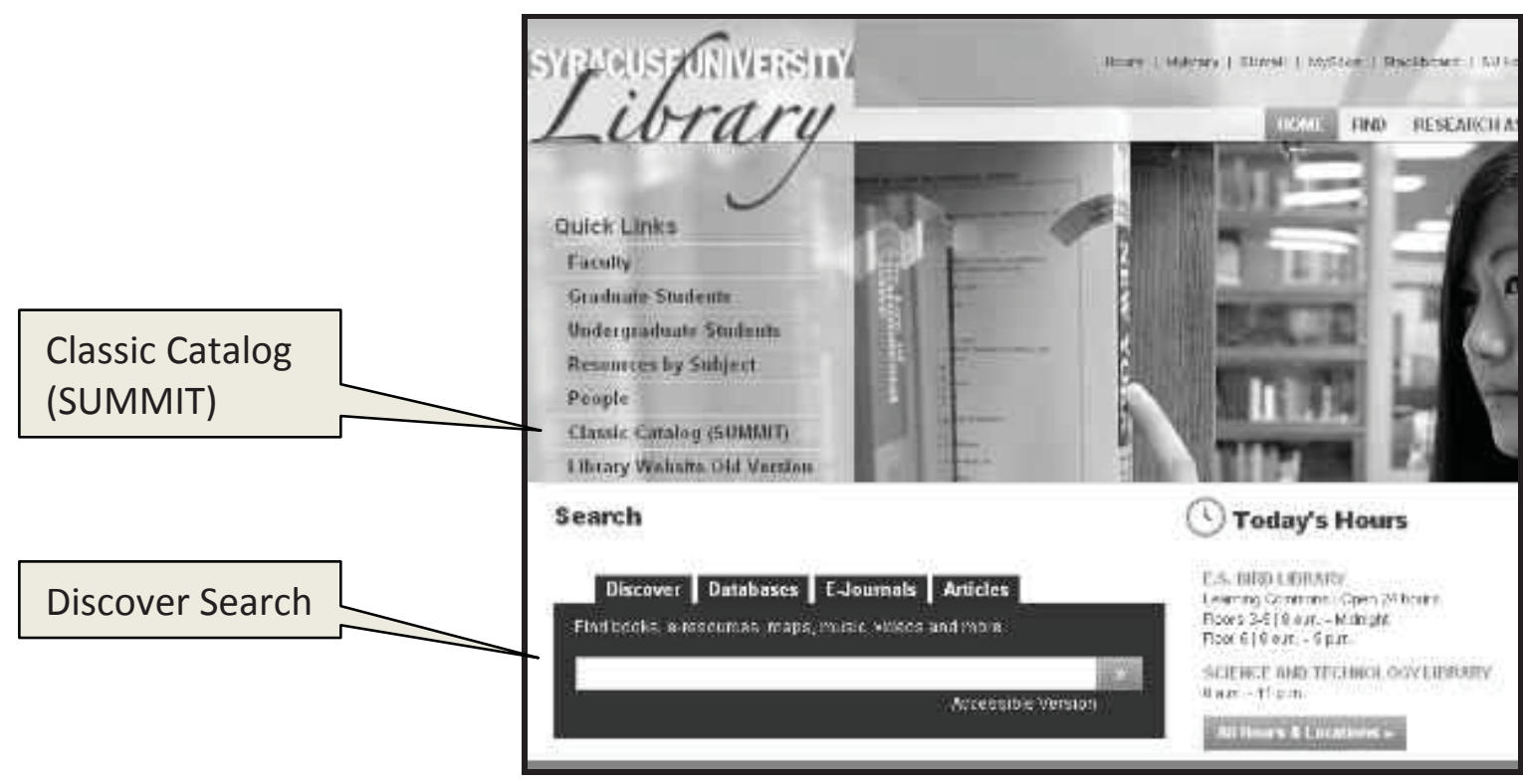


At this launch our new Discover search was the primary search box, defaulting to a keyword search in the Library's catalog. The Discover tool was added as a more user-friendly solution to the traditional, now Classic catalog. It is an Encore (Innovative Interfaces) overlay to the Voyager (Ex Libris) online catalog. Discover supports more robust keyword searching and offers faceted browsing within the search results. The link to the Classic catalog was moved to a menu of Quick Links. The classic version supports indexed title, author and subject heading searches and browsing. The tabbed presentation to other searches for library resources was also new, taking the user to a databases title search, an ejournal title search and an article search supported by a the MetaLib (Ex Libris) metasearch engine. The Article search conducts a federated search against three general article databases.

User tests with undergraduate and graduate students were conducted in the fall of 2009. We were surprised with the results. When asked to ascertain the availability of the novel Beloved by Toni Morrison, half of the students selected a record that was incorrect. They did not distinguish between the novel itself and a secondary source of literary criticism about the novel. Were students in a hurry and not reading the screen? Was the organization of the information on the screen distracting them, or was the relevancy of the search engine not as robust as others with which they were more familiar, i.e., Google or Amazon? These questions led to another. Would library staff fare better at the task of locating a specific title in the Library's catalog? Using the same testing protocol with library staff, we hypothesized that library staff would handle this question differently and be more successful. What was not expected were additional differences that emerged, indicating that students and librarians have differing mental models they apply to the use of the Library's website. These different models are informed by experience and knowledge of Library resources and search tool functionality.

\section{Methodology}

We conducted pilot tests with 3 students. After slight modification of the instrument, the user test was given to 10 students ( 3 undergraduates and 7 graduates). In the second phase of the research, the user test was conducted with 18 library staff members, divided for analysis into those who work with the public in reference and instruction and those who do not.

Student participants for this study were recruited from within the library building using prominent signage and a flash drive giveaway as incentive for participation. Library staff members were recruited for participation via an email solicitation and of the 18 who volunteered, 9 were experienced with reference or instruction (public services) and 9 were not.

All participants were asked to complete five tasks with a starting point of the Library's home page at library.syr.edu [Figure 1]. Tasks for the usability test were selected to represent typical tasks that users conduct as they look for and use library resources. The tasks were written to be simple and unambiguous. They were read aloud and provided in writing to each participant. The session was recorded using Morae software to capture the computer screen action.

- Locate the book Beloved by Toni Morrison. Is this book available for you to check out of the Library?

- Locate an electronic journal in the subject of psychology.

- Find a multi-media item, like a video, for a presentation you are doing on health and the college student.

- Find and access the full text of an article from the online journal Nature.

- Show me how you might locate first-hand accounts or primary resources (diaries, newspaper articles) by people who worked on the Erie Canal (1840-1860).

Described here are findings for two tasks, finding a book and locating primary resources. Upon analysis, these two tasks reflected differences in search behaviors most clearly. 
Figure 2 - Finding a Book

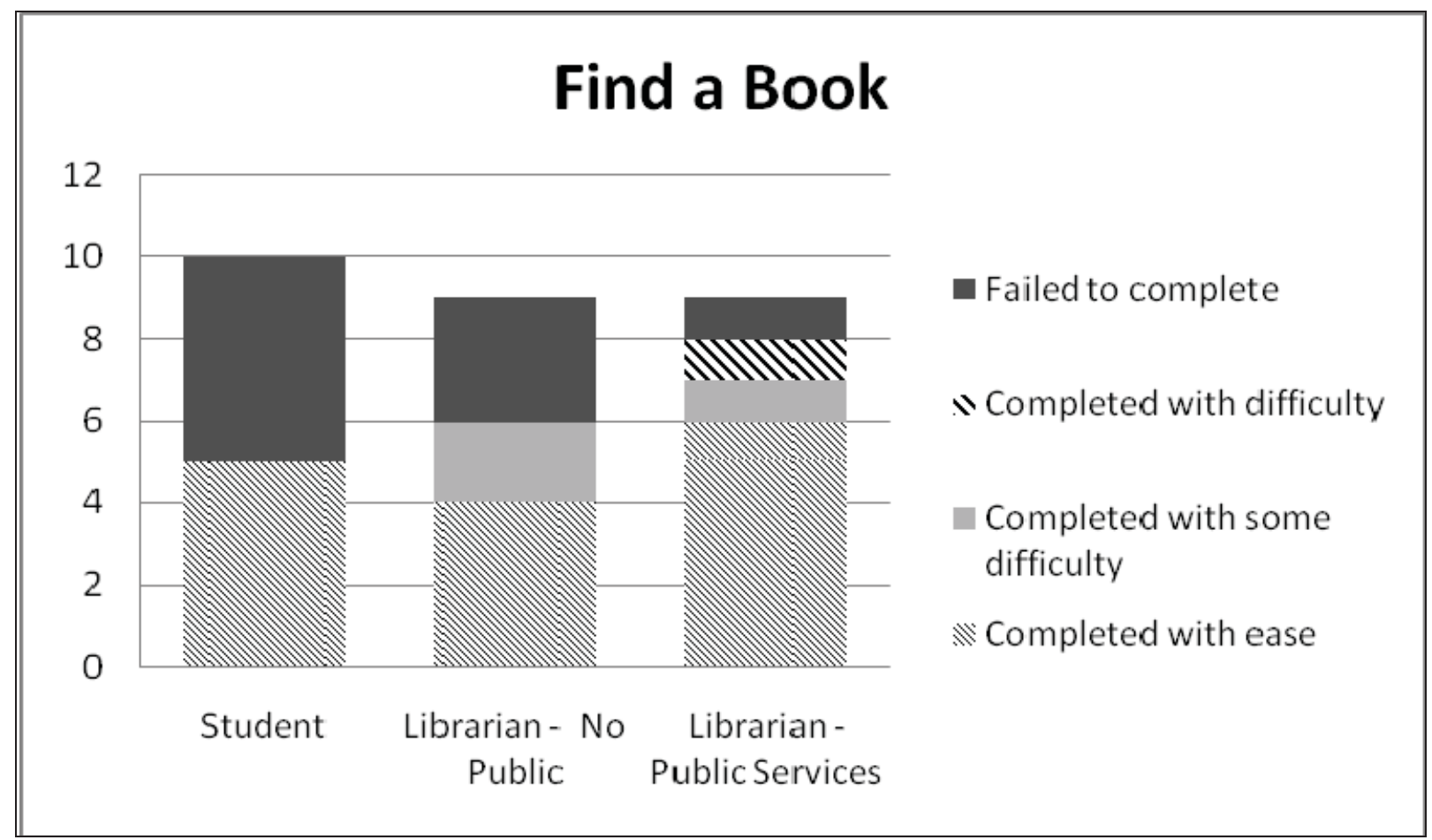

When asked to locate the book Beloved by Toni Morrison and to note its availability for check out, each student started their search with Discover. When searching, some students entered both author's name and book title, yielding satisfactory results. This syntax would result in an error if the Classic catalog was used. In only one example did a student invert the name of the author - most typed a variation of "beloved Toni Morrison." Students successful with this task completed it with ease. However, out of the 10 students, 5 did not identify the correct catalog record for this task, selecting a secondary source about the author's work.
In contrast to students, 9 out of 18 library staff members began their search for this book by navigating to the Classic catalog. Using this interface required staff to bypass the default search box on the Library's home and click on a link to the catalog. Some asked for permission to go to the more familiar old version of the Library's website, indicating that they were not yet confident in their use of the new catalog search tool. Others stated a preference for a more structured approach to their search, using the advanced search tools for author and title. As illustrated in Figure 2, Library staff were more successful with this task. 
Figure 3 - Finding a Primary Resource

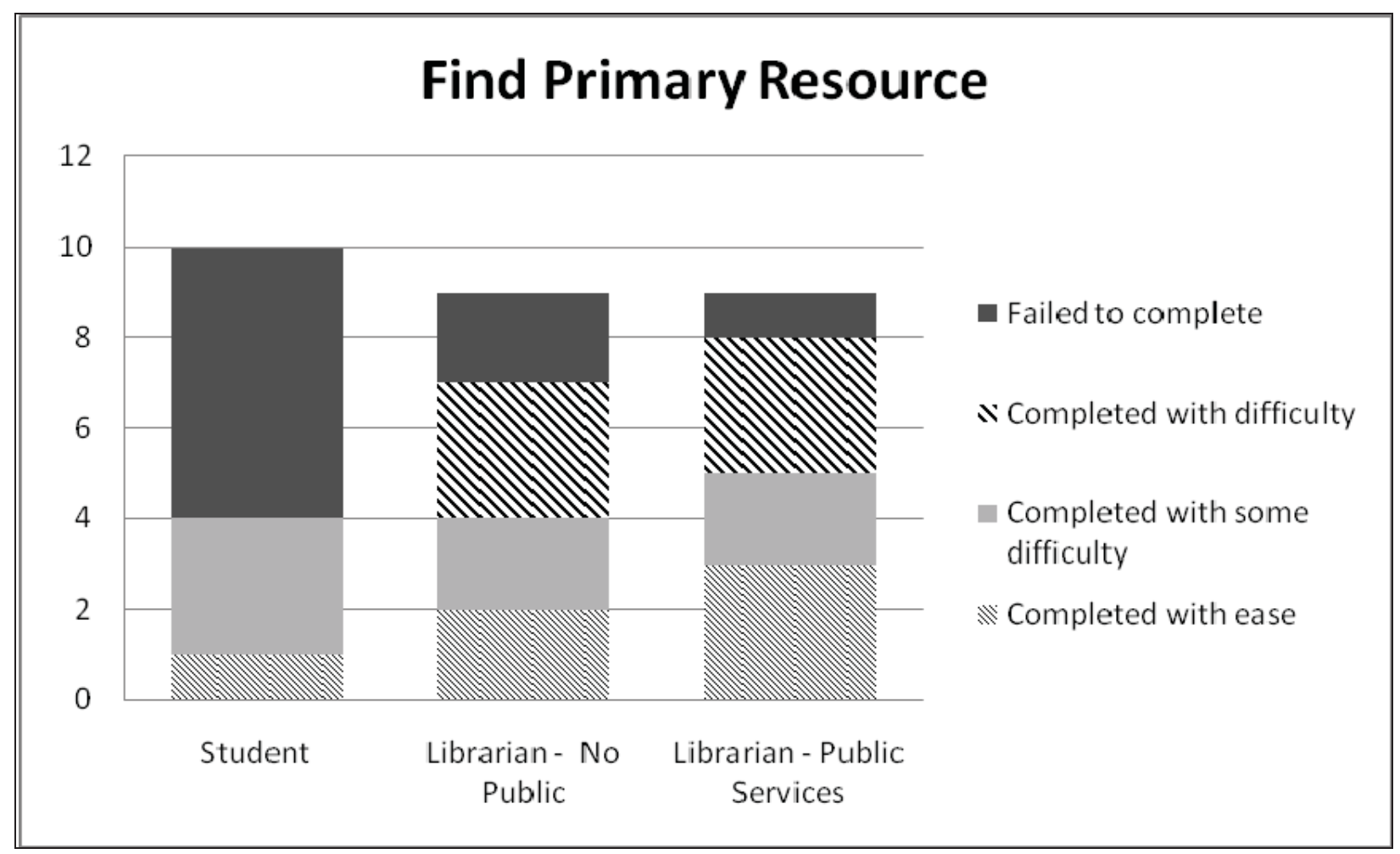

Users were also asked to locate a primary resource, described as a first-hand account of someone who worked on the Erie Canal. This question was written so participants did not need to know the term "primary resource,' nor the dates of the Erie Canal in history. Users of all types had less success with this question, even though it was more open ended than the task of finding a specific title. In this task, completion was defined not by locating a specific catalog item, but locating a resource that the participant deemed satisfactory.

Most students began this search with the Discover catalog. A few ventured beyond the default search box and navigated to the Articles search tab. None used the Classic catalog. Students who were successful with this task had additional knowledge about library research in primary materials--for instance that older newspapers might be found on microfilm. This was demonstrated by their selection of that format facet. Others used a search syntax that combined subject and format into a single search string. Expressions like "erie canal primary materials," or "articles by people who worked on the erie canal" were used.

Staff members used a variety of search tools to locate primary materials. 4 staff members bypassed the search box entirely and navigated instead to our Special Collections Research Center page, assuming that primary materials could be located there. Like students, staff depended on their knowledge of the nature of primary resources and used facets or limits.

In several cases, the library staff would suggest multiple strategies. After retrieving one record, they would return to the home page and start another navigational path-or suggest alternatives verbally. To some extent this behavior was skewed by the investigator's presence. It may also be that librarians do enjoy the process of searching, and are less ready to settle for something that is merely "good enough."

\section{Analysis}

For these search tasks, we saw differences between students and library staff in four aspects:

- Selection of search tools 
- Syntax used for searching

- Prior knowledge of library resource organization

- Level of searching persistence

Selection of search tools. All students started their search for a book using the default search box-the Discover tool. They did not explore the page for additional search options. Students unfamiliar with the site would have no way of knowing that there were two search tools available to them for searching the catalog content.

Library staff draw upon their knowledge of library holdings and search tool functionality when searching and navigating the website. We saw examples of this in their selection of the Classic catalog for known item searching, and their bypassing of the search box to seek information about special collections holdings of primary resource materials. In fact, staff may be less enthusiastic than students for trying out a new tool in the context of a usability "test" having more confidence in their abilities with the familiar tool. Even anticipating the difficulty of a new search tool indicates a difference in mind set.

Syntax used for searching. When searching within Discover for an author, students did not use special syntax, i.e. inverting the author's first and last names. Students were also more likely to use detailed language in the search box. For instance, they might include both the author's name and the title of the book. In searching for primary source material, they might add a specific format (i.e. diary) to the search query. We saw examples of students using the kind of syntax they have learned to use for searching Google. When they received unexpected results, they would add search terms rather than remove them. This tactic corresponds to Zhang's findings, where students aim to be precise and specific, using more words instead of one. ${ }^{8}$

\section{Prior knowledge of library resource} organization. Students often had trouble distinguishing between a catalog record for a book about Beloved by Toni Morrison and the actual novel. Our findings do not shed light on this difference, although it relates to findings at MIT that show accuracy improving with library experience. Students may be in a hurry.
Alternatively their "mental models" for relevancy may provide expectations that the first records would match their query - that a search for Beloved would put that title at the top of the list.

In searching for primary materials, both groups drew upon prior knowledge. For students, this was demonstrated in the use of facets to limit by format; for staff, it was demonstrated also by users navigating directly to an area of the website where primary resources are likely to be foundSpecial Collections. Staff also recognized that for this type of search, multiple resources might be available and persistence, as well as the trying of different strategies, is required.

Level of persistence. Persistence is demonstrated in the care with which the user reads the screen and evaluates the search results. It may be exhibited by trying different search strategies. When searching in a subject area, staff members demonstrate persistence and an interest in trying alternative strategies. Library staff took more time, on average, to locate materials. Their navigation through the systems was more deliberate and measured and frequently they verbalized their thoughts aloud. One of the differences between librarians and other users is the level of persistence that librarians bring to the search endeavor. Nothing is more gratifying than a complicated search, or strategizing about the path to the best or most comprehensive set of resources. This may not be the case for college students. They prefer finding over searching.

The differences in the use of tools and strategies are indicative of different mental models. It makes sense that those of us who use these systems frequently will develop more accurate mental models for the library information universe, even without formal education or training. The challenge is to recognize how our library-oriented models may not be those of our students. For example, in most information seeking with an Internet search engine, students have no need to ask themselves, "Is this a known item or a subject search?" Neither Google nor Amazon requires the searcher to distinguish between a known item and topical search. Students' firm mental models of how searches work set up expectations that a single tool and search query formulation will work for all types of information retrieval tasks. It makes sense, then, for our students to approach 
the top level search box as they would an Internet search engine. In our library portal design and instruction, we need to balance our search offerings and their presentation to accommodate alternative mental models for the online information universe in a way that leads to success more of the time.

\section{Implications for Web Design}

\section{Figure 4 - Updated Search Box}

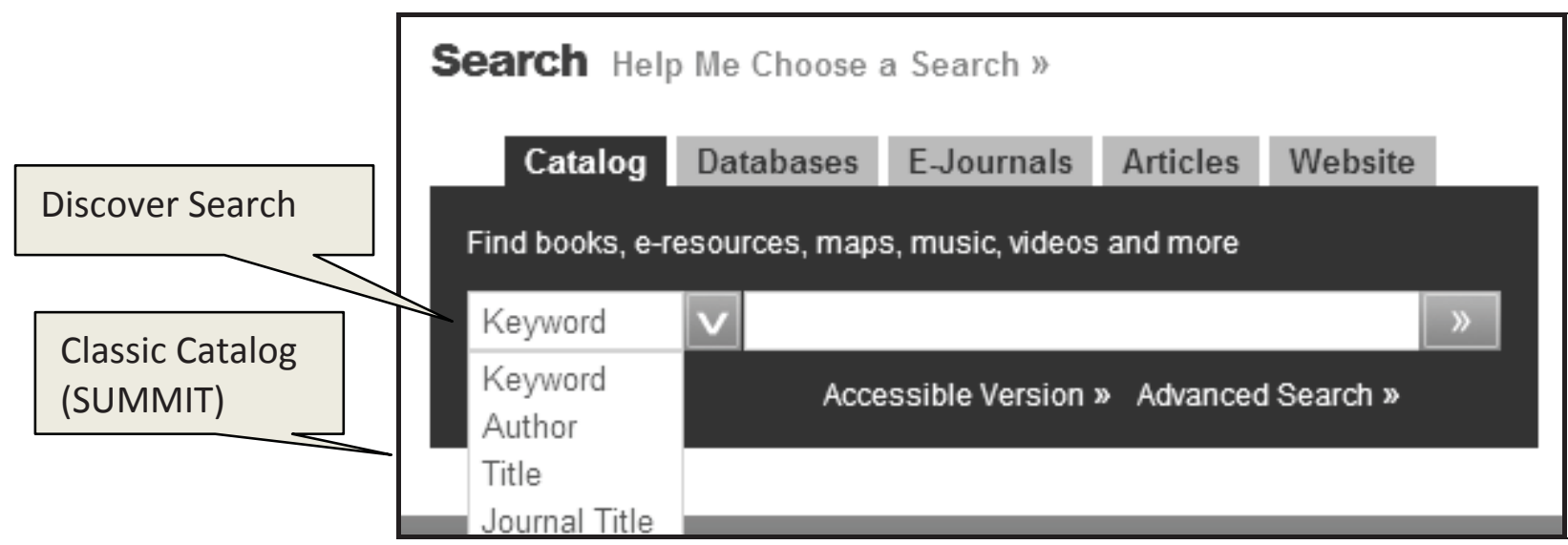

As illustrated in Figure 4, several changes were made to the search box. Changes were made based on the assumption that students would be more successful if they were better able to learn how the different search tools worked. We added a prominent "Help Me Choose a Search" page with a link near the search box. We made it easier for all users to access the Classic catalog. This improvement included collapsing the two catalog searches into a single search box. The keyword search defaults to Discover, the other searches go directly to the Classic catalog interface. Finally, we changed the tab label to Catalog.

It remains to be seen if this changes will be noticed and used or if students will continue to use the keyword search box for all types of searches. And they may also continue to have success, much of the time, with their Googleinfluenced search strategies.

Students' behavior when using the website is impacted by the search tools they know bestGoogle, Yahoo, Amazon or some other tool. They lack the experience with library systems and their less accurate mental models may hinder searching success. Our changes are designed to help the development of mental models about library resource searching for users. Research demonstrates that system cues and feedback from search results help users to formulate mental models. We might jumpstart that development by preventing "dead ends" for searchers. When possible, we should configure "error" messages in ways that provide suggestions and appropriate links for help.

\section{Implications for Instruction and Reference}

Designing better interfaces requires library understanding of its users. How can library staff enhance their own understanding of students' mental models? We conduct usability testing with students. We insure that our web development projects include student participation. We listen to their questions during instruction and reference sessions. When students come to the reference desk, we typically ask how we can help them.

In addition to these measures, what if we started a reference interview in a different way? For instance, when the student sits down for a consultation, what if the librarian first asked to see the search strategies already pursued? What if the reference interview started with the request, "Show me what you did"? A few interactions like 
this might go far in helping library staff gain a more accurate picture of the processes students use to conduct a search-their mental models.

Our testing indicates that students' mental models for the information universe do not contain separate categories for structured searches (indexed by author, title and subject headings) and non-structured, or keyword searches. When approaching a search task, students may not analyze the type of search they are conducting. They may not ask themselves, "Is this a known item?" or "Am I conducting a subject-related search?"- And yet in our presentation of search tools, and in our instruction, we ask that the user consider this aspect before they even begin. To create usable portals to library content, we must consider the different stance we bring to information seeking than that of our students. Our aim must be to bridge the gap between our own knowledge of library sources and search tools and those our students bring with them. Our practical challenge is developing online interfaces and instructional strategies that foster in our users more accurate mental models that support their effective exploration and discovery of library resources that best meet their information needs.

—Copyright 2011 Nancy B. Turner

\section{Notes}

1. Joan Lippincott, "Net Generation Students and Libraries' IN Educating the Net Generation,"
In Education the Net Generation, eds. Diana

G. Oblinger and James L. Oblinger

(Washington DC: EDUCAUSE, 2005), 13.113.15.

2. Brenda Reeb and Susan Gibbons, "Students, Librarians, and Subject Guides: Improving a Poor Rate of Return," portal: Libraries and the Academy 4, 1 (2004): 123-130.

3. Tracy Babridge, Millicent Gaskell and Amy Stout, "Information Seeking through Students' Eyes: The MIT Photo Diary Study," College \& Research Libraries 69 (2008): 510522.

4. Yan Zhang, "Undergraduate Students' Mental Models of the Web as an Information Retrieval System," Journal of the American Society for Information Science and Technology59, 13 (2008): 2087-2098.

5. Ibid., 2096.

6. Jakob Nielsen, "Mental Models for Search Are Getting Firmer," http:/ / www.useit.com/ alertbox/20050509.html.

7. Alexandra Dimitroff, "Mental Models Theory and Search Outcome in a Bibliographic Retrieval System," Library and Information Science Research 14 (1992): 141-156.

8. Zhang, 2094. 